OPEN ACCESS

Edited by:

Aziz Ullah,

Kohat University of Science and

Technology, Pakistan

Reviewed by:

Armando Costa Duarte

University of Aveiro, Portugal

Ghazala Nawaz,

Kohat University of Science and

Technology, Pakistan

*Correspondence:

Celine Guéguen

celine.gueguen@usherbrooke.ca

Specialty section:

This article was submitted to

Environmental Toxicology,

a section of the journal

Frontiers in Environmental Science

Received: 23 May 2018 Accepted: 06 December 2018

Published: 07 January 2019

Citation:

Mangal $V$, Phung T, Nguyen TQ and

Guéguen C (2019) Molecular

Characterization of Mercury Binding

Ligands Released by Freshwater

Algae Grown at Three Photoperiods.

Front. Environ. Sci. 6:155

doi: 10.3389/fenvs.2018.00155

\section{Molecular Characterization of Mercury Binding Ligands Released by Freshwater Algae Grown at Three Photoperiods}

\author{
Vaughn Mangal ${ }^{1}$, Ta Phung ${ }^{2}$, Thien Q. Nguyen ${ }^{2}$ and Celine Guéguen ${ }^{2,3 *}$ \\ ${ }^{1}$ Environmental and Life Sciences Graduate Program, Trent University, Peterborough, ON, Canada, ${ }^{2}$ Chemistry Department, \\ Trent University, Peterborough, ON, Canada, ${ }^{3}$ Département de Chimie, Université de Sherbrooke, Sherbrooke, QC, Canada
}

Interactions between algal derived dissolved organic matter (DOM) and mercury $(\mathrm{Hg})$ are crucial for understanding the fate, transport, and bioavailability of $\mathrm{Hg}$ to methylating microorganisms. For the first time, high resolution mass spectrometry (Q-Exactive Orbitrap) was used to examine $\mathrm{Hg}$ binding ligands released by Chlorella vulgaris, Chlamydomonas reinhardtii, and Scenedesmus obliquus grown at three light:dark photoperiods (i.e., 12:12, 16:8, and 20:4 h). Van Krevelen diagrams showed a significant increase in carbohydrate and protein DOM and a decrease in released lipid-like molecules as light exposure increased. $\mathrm{Hg}$ binding DOM were initially in the form of $\mathrm{CHO}$ molecular formulas whereas a shift to higher light durations prompted more $\mathrm{Hg}$ to be complexed to $\mathrm{CHON}$ and $\mathrm{CHONS}$ DOM structures. Despite an overall change in bulk DOM composition, molecular similarities existed in Hg binding DOM as light exposure increased. Hg binding ligands were more similar based on the exposed light duration than based algal species, suggesting growth photoperiods influence $\mathrm{Hg}$ binding more than algal taxa. $\mathrm{Hg}$ binding DOM at 16:8 and 20:4 h growth cycles were more aromatic and homologous in nature when compared to darker growth conditions that resulted in smaller, more aliphatic Hg-DOM complexes rich in sulfur and thiols. Together, these results highlight the importance of photoperiod on the composition of released DOM and its complexation with $\mathrm{Hg}$.

Keywords: dissolved organic matter, algal organic matter, mercury, high resolution mass spectrometry, mercury speciation

\section{INTRODUCTION}

Anthropogenic activities have increased both atmospheric and aquatic mercury ( $\mathrm{Hg})$ concentrations worldwide (Andersson et al., 2008; Park et al., 2008; Lavoie et al., 2013). Mercury is of major concern due to its conversion to neurotoxin methylmercury (MeHg) that can be biomagnified and bioaccumulated in the food chain leading to adverse health effects by humans and wildlife (St. Louis et al., 2007; Lavoie et al., 2013). The conversion of $\mathrm{Hg}$ to $\mathrm{MeHg}$ was originally thought to be an exclusively anoxic process; however, studies have suggested the conversion $\mathrm{Hg}$ to $\mathrm{MeHg}$ can occur in oxic aquatic settings of polar waters (Larose et al., 2010; Lehnherr et al., 2011) and in algal biofilms (Parks et al., 2013; Leclerc et al., 2015). Studies have also explored how environments abundant in algal dissolved organic matter (DOM) yielded more MeHg formation 


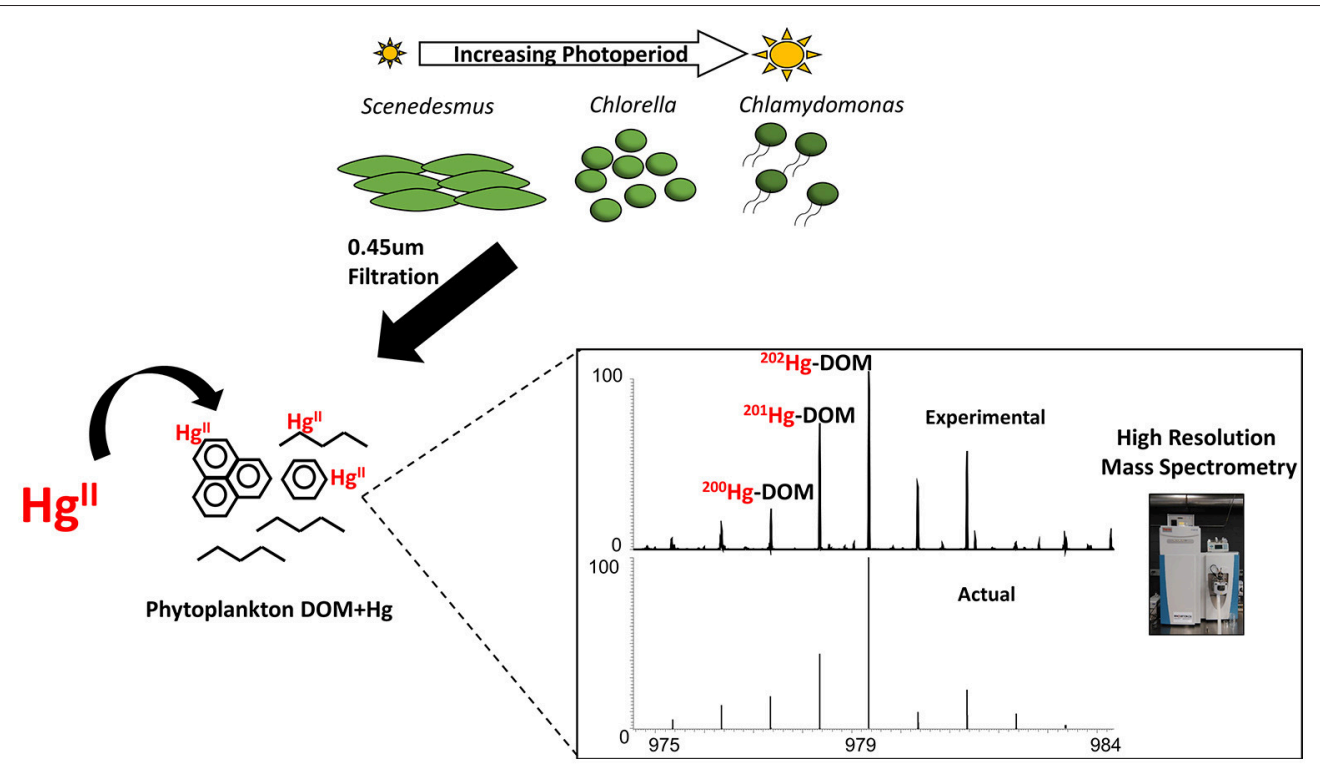

GRAPHICAL ABSTRACT | Work-flow depicting the harvesting of algal-DOM at various growth photoperiods and the identification of Hg-DOM complexes using Orbitrap high resolution mass spectrometry.

than in environments dominated by terrestrially derived DOM (Bravo et al., 2017). In the Canadian Arctic, a subsurface maximum in $\mathrm{MeHg}$ concentration was found to be within metabolite enriched halocline layers abundant in lower trophic level biota (Wang et al., 2018). We are just beginning to understand that algal DOM has a profound role on $\mathrm{MeHg}$ formation, yet many gaps in knowledge remain around the specific role that algal DOM plays on $\mathrm{Hg}$ binding and bioavailability.

Algae is a diverse group of autotrophic microorganisms that has an essential role in the carbon cycle by converting abiotic to biotic energy through the production of organic substrates and dissolved organic nitrogen (DON) that largely support other prokaryotic and heterotrophic organisms (Wada and Hama, 2013; Monier et al., 2015). Algal DOM contains an abundance of nitrogen, trace amounts of sulfur, and carboxyl functional groups that can strongly bind to $\mathrm{Hg}$ and influence its complexation (Skyllberg and Drott, 2010). Increasing global temperatures coupled with thermal reorganization of water columns resulting from anthropogenic factors will also select for small microalgae, further amplifying algae's role in controlling metals in aquatic systems (Ansotegui et al., 2003; Winder and Sommer, 2012; Bravo et al., 2017). These lower molecular weight organic substrates present in algal DOM have been shown to play a key role in $\mathrm{Hg}$ bioavailability for MeHg production (Lancelot, 1984; Le Faucheur et al., 2014; Leclerc et al., 2015; Mangal and Guéguen, 2015; Mangal et al., 2016). The interactions between algal DOM and $\mathrm{Hg}$ remain a crucial step in understanding the fate of $\mathrm{Hg}$; however, environmental variables also play a crucial role on the composition of DOM that governs $\mathrm{Hg}$ binding.

Biotic and abiotic factors including $\mathrm{pH}$, light exposure, and microbial community structure can influence the composition of released DOM by autotrophs (Frost, 1987; Leu et al., 2015). In polar regions, the rapid increase in spring daylight hours coincides with algal growth periods and marks the beginning of fresh autochthonous DOM entering northern aquatic ecosystems (Leu et al., 2015). Photo exposure periods transition from $12 \mathrm{~h}$ of daylight in early spring (i.e., April) to periods of $24 \mathrm{~h}$ of full daylight at the summer solstice in June (LaPerriere et al., 1978; Frost, 1987). Light-induced stress can result in the formation of reactive oxygen species (ROS) for many algae in the event of prolonged or limited photo exposure (Tian and $\mathrm{Yu}, 2009$ ). To help cope with the formation of ROS radicals, sulfur rich amino acids, glutathione (GSH), and larger peptides such as phytochelatins are generated (Tian and Yu, 2009). These changes in algal metabolism and community associated with higher light exposure during spring blooms can result in compositional changes of DOM and dissolved sulfur concentrations leading to profound implications on Hg binding (Maranon et al., 2005; Thornton, 2014).

Although techniques such as fluorescence and absorbance spectroscopy can provide an adequate preliminary assessment of DOM bulk properties, these techniques are biased to light absorbing DOM moieties (Koch and Dittmar, 2006; Chen et al., 2017). Evaluating DOM-Hg interactions has been conducted using Fourier-transform infrared spectroscopy, and X-ray absorption (Chen et al., 2002, 2017; Schartup et al., 2015), but lack the specificity of exact composition and molecular properties of DOM. High resolution mass spectrometry (HRMS) has been used to provide compound level information for humic substances (HS), algae, and DOM from a variety of temperate and Northern aquatic environments (Koch and Dittmar, 2006; Tremblay et al., 2007; Bhatia et al., 2010; D'Andrilli et al., 2013; Kellerman et al., 2015; Mangal et al., 2016; Osterholz et al., 2016). 
HMRS has recently become recognized for its ability to detect organometallic complexes including iron, copper and $\mathrm{Hg}$ (NguSchwemlein et al., 2014; Waska et al., 2016; Chen et al., 2017). While earlier studies have explored Hg-HS interactions (Chen et al., 2017), algal DOM-Hg interactions have not been addressed yet. This study aims to address these gaps in knowledge by using a multi-faceted analytical approach to (1) understand how algal DOM changes in composition with varying photo exposure periods that mimic natural subpolar transitions (Van Grrest et al., 2007; Leya et al., 2009) and (2) to explore what the compositional changes in algal DOM have on Hg binding (Graphical Abstract).

\section{MATERIALS AND METHODS}

\section{Algal Growth and DOC Concentrations}

Laboratory grown cultures of Chlamydomonas reinhardtii (C. reinhardtii), Chlorella vulgaris (C. vulgaris) and Scenedesmus obliquus (S. obliquus) were obtained from the Canadian Phycological Culture Center (CPCC) in Waterloo, Ontario and grown using a high salt media (HSM) for C. reinhardtii (Sueoka, 1960) and a bold basal media (BBM) for C. vulgaris and S. obliquus (Sadiq et al., 2011). These microalgae thrive in eutrophic, nutrient rich waters and can withstand large temperature fluctuations of shallow freshwaters; two important factors to consider with warming temperatures and increasing nutrient loads in freshwater environments (Ansotegui et al., 2003; Winder and Sommer, 2012). Growth conditions included photoperiods of low, standard, and high regimes (12:12, 16:8, and 20:4 h, light:dark cycle; respectively) at a fixed light intensity of $90-100 \mu \mathrm{mol}$ photons $\mathrm{m}^{-1} \mathrm{~s}^{-1}$ and a temperature of $21^{\circ} \mathrm{C}$. DOM was sampled at mid exponential growth phase as determined by hemocytometer cell counting. DOM was harvested during the fourth hour of the light phase for all light regimes and immediately filtered through a pre-combusted $0.7 \mu \mathrm{m}$ glass fiber filter (GF/F Whatman) into acid washed and pre-combusted glassware. Biological triplicates of algal-derived DOM were collected at all three light regimes. Filtered algal-derived DOC concentrations were measured using a total organic carbon (TOC) analyzer and fixed to $1 \mathrm{mg} \mathrm{C}$. $\mathrm{L}^{-1}$ for further analyses (Table S1).

\section{qBBr Titration}

Fresh stock solution of $0.001 \mathrm{~mol} \mathrm{~L}^{-1} \mathrm{qBBr}$ (SigmaAldrich) was prepared daily in amber glass bottle covered in aluminum foil. A series of $\mathrm{qBBr}$ standard addition solutions was prepared by mixing $5 \mathrm{~mL}$ of DOM samples at increasing volumes of $\mathrm{qBBr}$ (final concentrations ranging from 4.98 to $152.54 \mu \mathrm{mol}$ $\mathrm{L}^{-1}$ ). The solutions were covered with aluminum foil and mixed for an hour at room temperature. qBBr-equivalent thiol concentrations were determined at fixed excitation and emission wavelengths (380 and $470 \mathrm{~nm}$, respectively) using a Fluoromax4 spectrophotometer (Horiba Jobin Yvon) (JoeWong et al., 2012; Mangal and Guéguen, 2015). Since qBBr binds to thiols at a 1:1 molar ratio, the level of $\mathrm{qBBr}$ saturation in samples corresponded to thiol concentration. Total thiol concentrations were determined using non-linear piece-wise regression (SigmaPlot, v12.5) $\left(0.97<R^{2}<0.99\right.$; $p<0.05$ ) (Joe-Wong et al., 2012; Mangal and Guéguen, 2015).

\section{High Resolution Mass Spectrometry}

The molecular composition of algal-derived DOM was determined using the Orbitrap Q Exactive (Thermo Fisher Scientific, Bremen, Germany) equipped with a heated electrospray ionization (HESI) source. The resolving power was 140,000 (full width half maximum @ m/z 200). Prior to injection, samples were normalized to a DOC concentration of $1 \mathrm{mg} \mathrm{C} \mathrm{L}^{-1}$, diluted to a 50:50 sample to $\mathrm{MeOH}$ ratio with ultrapure $\mathrm{MeOH}$ (99.9\% HPLC grade; Sigma Aldrich) and the $\mathrm{pH}$ was adjusted to 6.8 with ultrapure $\mathrm{NaOH}$ (Sigma Aldrich). Samples were injected at a consistent flow rate of $50 \mu \mathrm{L} \mathrm{min}-1$ with an electrospray needle voltage of $4 \mathrm{kV}$ and a heated capillary temperature of $300^{\circ} \mathrm{C}$ in positive ionization mode (Mangal et al., 2016; Sipler et al., 2017). Sodium trifluoroacetate (NaTFA, Sigma-Aldrich 98\%) was added as an internal standard in each sample and externally calibrated twice a day to ensure exact mass accuracy between a mass range of $200-1,000 \mathrm{~m} / \mathrm{z}$. Samples were acquired for a minimum of $5 \mathrm{~min}$ to allow for 200 scans to be co-added in the data post analysis stage using the Thermo Xcalibur Qual Browser (3.0.63) software. Background signals from algal growth media and $\mathrm{MeOH}$ were subtracted prior to formula assignment. Elemental constraints for formula assignment were: ${ }^{12} \mathrm{C}(0-50),{ }^{1} \mathrm{H}(0-100),{ }^{16} \mathrm{O}(0-30),{ }^{14} \mathrm{~N}(0-7)$, ${ }^{32} \mathrm{~S}(0-4)$, and ${ }^{23} \mathrm{Na}(0-1)$ using the odd nitrogen rule. Molecular formulas were validated based carbon and sulfur isotopes $\left({ }^{13} \mathrm{C}\right.$ and ${ }^{34} \mathrm{~S}$ ) and signal to noise ratios were $\geq 4$ within $\pm 2 \mathrm{ppm}$ exact mass error (Figures S1,S2) (Ohno and Ohno, 2013; Herzsprung et al., 2016; Mangal et al., 2017). An in-house Matlab script (SI) was used to determine the abundance of seven compound classes: lipid $(0.01 \leq \mathrm{O} / \mathrm{C} \leq 0.1 ; 1.5 \leq \mathrm{H} / \mathrm{C} \leq 2.0)$, unsaturated hydrocarbons $(0.01 \leq \mathrm{O} / \mathrm{C} \leq 0.1 ; 0.75 \leq \mathrm{H} / \mathrm{C} \leq 1.5)$, condensed aromatic structures $(0.01 \leq \mathrm{O} / \mathrm{C} \leq 0.65 ; 0.25 \leq \mathrm{H} / \mathrm{C} \leq 0.75)$, protein $(0.1 \leq \mathrm{O} / \mathrm{C} \leq 0.65 ; 1.5 \leq \mathrm{H} / \mathrm{C} \leq 2.3 ; \mathrm{N} \geq 1)$, lignin $(0.1 \leq \mathrm{O} / \mathrm{C} \leq 0.65 ; 0.75 \leq \mathrm{H} / \mathrm{C} \leq 1.5)$ with no heteroatoms (only $\mathrm{CHO})$, tannins $(0.65 \leq \mathrm{O} / \mathrm{C} \leq 0.85) ;(0.75 \leq \mathrm{H} / \mathrm{C} \leq$ $1.5)$ and carbohydrates $(0.65 \leq \mathrm{O} / \mathrm{C} \leq 1.0 ; 1.5 \leq \mathrm{H} / \mathrm{C} \leq 2.5)$, similar to previous studies (Kim et al., 2003; Ohno and Ohno, 2013; Mangal and Guéguen, 2015; Mangal et al., 2017). Atomic ratios and elemental averages of $\mathrm{O} / \mathrm{C}, \mathrm{H} / \mathrm{C}, \mathrm{S} / \mathrm{C}, \% \mathrm{C}, \% \mathrm{H}, \% \mathrm{O}$, $\% \mathrm{~N}, \% \mathrm{~S}, \mathrm{~m} / \mathrm{z}$, double bond equivalence (DBE, Equation 1) modified aromaticity index ( $\mathrm{AI}_{\text {mod }}$, Equation 2$)$ and the nominal oxidation state of carbon (NOSC, Equation 3) were all calculated to interpret the changes in aromaticity and oxidation state of DOM (Koch and Dittmar, 2006; Riedel et al., 2013; Roth et al., 2013, 2015).

$$
\begin{array}{r}
\mathrm{DBE}=1+\frac{1}{2}(2 \mathrm{C}-\mathrm{H}+\mathrm{N}+\mathrm{P}) \\
\mathrm{AI}_{\text {mod }}=\frac{1+\mathrm{C}-0.5 \mathrm{O}-\mathrm{S}-0.5 \mathrm{H}}{\mathrm{C}-0.5 \mathrm{O}-\mathrm{S}-\mathrm{N}-\mathrm{P}} \\
\mathrm{NOSC}=4-\left[\frac{4 \mathrm{C}+\mathrm{H}-3 \mathrm{~N}-2 \mathrm{O}-2 \mathrm{~S}}{\mathrm{C}}\right]
\end{array}
$$




\section{Mercury Detection}

$\mathrm{Hg}$ solutions were prepared by mixing $2.5 \times 10^{-6} \mathrm{~mol} \mathrm{~L}^{-1}$ of $\mathrm{Hg}$ $\left(\mathrm{NO}_{3}\right)$ (AAS grade) with $1 \mathrm{mg} \mathrm{C} \mathrm{L} \mathrm{L}^{-1}$ of organic ligand (i.e., algal DOM or L-Cysteine; SigmaAldrich) and kept in the dark for at least $24 \mathrm{~h}$ prior to analysis. A $\mathrm{Hg}$ concentration of $2.5 \times 10^{-6} \mathrm{~mol}$ $\mathrm{L}^{-1}$ was found to be suitable to confidently identify less abundant $\mathrm{Hg}$ isotopes required for unambiguous peak identification. It should however be noted that the molar ratio used in this study was higher than in environmental settings but comparable to that used in previous Orbitrap studies (Ngu-Schwemlein et al., 2014). The $\mathrm{pH}$ solution was fixed to 6.8 with ultrapure $\mathrm{NaOH}$. For algal-derived DOM, blanks samples $(\mathrm{MeOH}+\mathrm{Hg}, \mathrm{HSM}+$ $\mathrm{Hg}$, and $\mathrm{BBM}+\mathrm{Hg}$ ) were evaluated and subtracted from $\mathrm{Hg}-$ Cysteine and $\mathrm{Hg}-\mathrm{DOM}$ and samples, respectively. To detect $\mathrm{Hg}$ containing compounds, ${ }^{202} \mathrm{Hg}$ and ${ }^{200} \mathrm{Hg}$ isotopes were added to the elemental constraints for formula assignment, comparable to previous ESI HRMS Hg studies (Chen et al., 2017). The software Winnow (Doran and LeBlanc, 2016) was used to detect 2 isotopologues of $\mathrm{Hg}\left({ }^{200} \mathrm{Hg}\right.$, and $\left.{ }^{202} \mathrm{Hg}\right)$. Only peaks with a Winnow score $>50 \%$ were utilized to confidently identify $\mathrm{Hg}$ containing DOM compounds in Xcalibur Isotope simulation (3.0.63). In addition, the ratio ${ }^{200} \mathrm{Hg}:{ }^{202} \mathrm{Hg}$ were calculated in organic ligand samples and compared to the theoretical ratio of 0.76 (Chen et al., 2017). For our experiments, if an experimental ratio between ${ }^{200} \mathrm{Hg}:{ }^{202} \mathrm{Hg}$ ratios was $>0.55$, within $5 \mathrm{ppm}$ error based on exact mass, and scored $>0.65$ using Winnow, that $\mathrm{Hg}$ peak was considered significant.

\section{Statistical Analyses}

Multivariable linear regression model II major axis (MA) analyses were conducted when comparing $\mathrm{qBBr}$ reactive thiol concentrations with HRMS \%S values as both variables contained intrinsic errors (Legendre, 2014). A one-tailed permutation test was conducted using the lmodel 2 package in $\mathrm{R}$ statistical computing (3.2.2) and $n=99$ at $95 \%$ confidence interval. When examining changes in algal DOM compound classes both between species and at different light regimes, a $t$-test was conducted where significance was evaluated at $p<0.05$ and a Shapiro-Wilk normality statistic was used. Hg binding DOM molecules between algal taxa and various growth photoperiods were compared using a principal component analysis (PCA) through the FactoMineR package of R(v3.4.1) (Le et al., 2008). A correlation matrix was utilized for the PCA as HRMS variables such as $\% \mathrm{~S}, \mathrm{AI}_{\text {mod }}, \mathrm{DBE}$ and $\mathrm{qBBr}$ reactive thiols were all derived from a HRMS platform.

\section{RESULTS AND DISCUSSION}

\section{Changes in DOM Composition With Increased Light Exposure}

A total of 416-1960 mass peaks were found across biological triplicates (Figures S3-S5). The mass peaks were mainly comprised of singly charged peaks and all detected sodium adducts were omitted from further analyses. As photoperiods increased, $\mathrm{O} / \mathrm{C}$ ratios increased from $(0.20 \pm 2.09) \times 10^{-3}$ at $12: 12$ to $(0.21 \pm 8.03) \times 10^{-3}$ at $16: 8$ and then to $(0.23 \pm 0.01) \times 10^{-3}$ at 20:4 for C. vulgaris (Figure 1A). A similar trend was observed for C. reinhardtii with the 20:4 growth conditions producing more oxygenated compounds than at 12:12 $\left[p<0.05 ;(0.22 \pm 3.16) \times 10^{-3}\right.$ vs. $\left.(0.28 \pm 0.02) \times 10^{-3}\right]$. For $S$. obliquus, the average $\mathrm{O} / \mathrm{C}$ ratio was maximum at light conditions of $16: 8$ [i.e., $(0.24 \pm 4.01) \times 10^{-3}$ ]. Although no significant change in $\mathrm{H} / \mathrm{C}$ ratios were observed between algal species, C. reinhardtii at the $16: 8$ photoperiod did prompt a significant maximum in hydrogenated compounds where $\mathrm{H} / \mathrm{C}$ ratios peaked at $1.99 \pm 0.01$ (Figure 1B). N/C ratios were significantly greater at the lowest light regime for all algal species $(p<0.05$; Figure 1C). S/C ratios were the lowest at 16:8 growth conditions for both $C$. vulgaris and S. obliquus and significantly greater at 12:12 (Figure 1D, $p<0.05$ ). For all algal taxa, $\mathrm{AI}_{\text {mod }}$ values (Figure 1E) were the lowest at 16:8 growth conditions suggesting the preferential release of more aliphatic compounds. $\mathrm{qBBr}$ titrations revealed significant increases in $\mathrm{qBBr}$ active thiol concentrations for $C$. vulgaris and $C$. reinhardtii $(p<0.05)$ but these trends were not observed for S. obliquus (Table S2). A significant relationship was observed between $\mathrm{qBBr}$ equivalent thiol concentrations and the $\% \mathrm{~S}$ contribution reported by Orbitrap ( $p<0.05 ; R^{2}=0.86$ ) suggesting that reactive thiols were a significant fraction of S-containing compounds in algal DOM (Figure S6). NOSC values were the most negative at 16:8 growth periods for both $C$. vulgaris and $C$. reinhardtii indicating a shift in reactivity from nonpolar at 16:8 to more polar compounds at both light extremes (Figure 1F), consistent with previous studies (Riedel et al., 2012; Roth et al., 2013, 2015). Although photo-oxidative stress was not explicitly measured, a higher degree in photorespiration caused by photo-oxidative stress has been proposed as a mechanism of increased carbon loss in algae (Yamada et al., 2012; Thornton, 2014) congruent with a significant increase in DOC concentrations (Table S1) and \%C from 16:8 to 20:4 (Figure S7A). Across all algal taxa, $\% \mathrm{H}$ and $\% \mathrm{O}$ were significantly greater at 16:8 $(p<0.05$; Figures S7B,C).

For each alga, the abundance of each DOM compound class based on van Krevelen diagrams differed across light durations (Figure 2; Figure S8). The lignin abundance increased by a factor of 2.8, 1.4, and 0.79 in C. reinhardtii, C. vulgaris and S. obliquus, respectively (Figure 2A). While lignin is known to provide cell wall support (Martone et al., 2009), the active secretion of these phenolic and polyphenolic compounds has been reported as a possible source of non-vascular plant derived lignin (Hernes et al., 2007). Protein content was the most abundant compound class for all algae (34.1-48.7\%) and increased as photoperiods increased (Figure 2B). Across biological triplicates, the abundance of HRMS-based protein material increased for all algae as photoperiods increased ranging from 34.1 to $48.8 \%$. Proteinaceous material in the form of amino acids, larger peptides and amino sugars serve as crucial components of the total DON and are the predominant compound class accounting for more than $50 \%$ of the material released by algae (Bronk et al., 2007; Yamada et al., 2012; Thornton, 2014). Across all algal taxa, the 20:4 growth conditions showed greater protein content compared to $12: 12$ conditions $(p<0.05)$ likely caused by a shift in algal metabolism where a change from lipid and polysaccharide synthesis to protein synthesis occurs during periods of stress (Lancelot, 1984; Guschina and Harwood, 2006). 

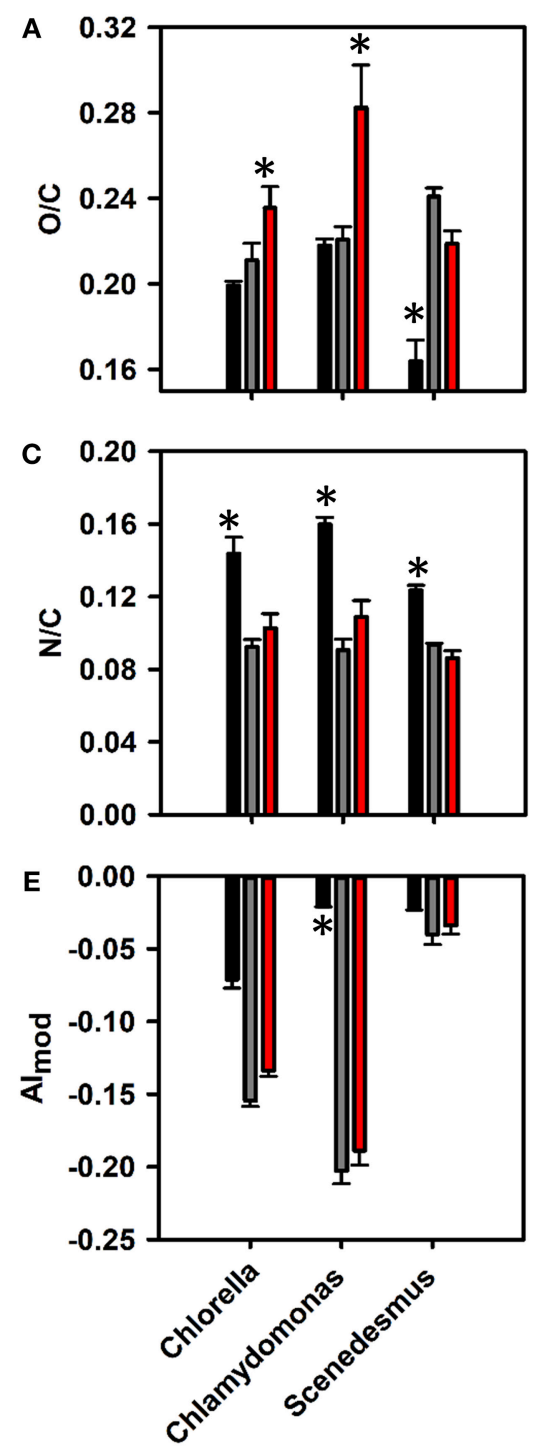
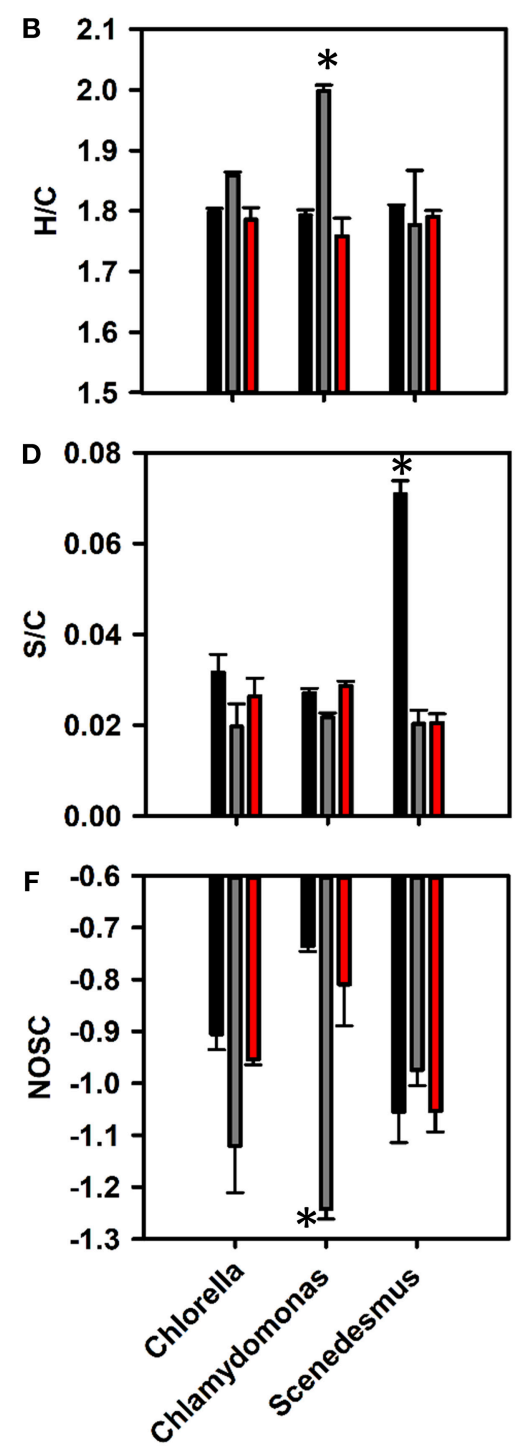

2:12 Photoperiod 16:8 Photoperiod 20:4 Photoperiod

FIGURE 1 | Bar graphs representing changes in atomic ratios such as O/C (A), H/C (B), N/C (C), and S/C (D) along with changes in compositional properties Al mod (E) and NOSC (F) at 12:12 (black), 16:8 (gray), and 20:4 (red) light regimes for $C$. vulgaris, C. reinhardtii, and S. obliquus. Error bars for all light:dark cycles are based on biological triplicates $(n=3)$. *Represents a signficant difference $(p<0.05)$ in bulk DOM parameters between $12: 12$ and $20: 4 \mathrm{~h}$ for each algae.

The fatty acid content of algae was higher at lower light exposure (Guschina and Harwood, 2006) where a 30-50\% decrease in lipid abundance was observed with increasing photoperiods (Figure 2C). All algae in this study have been known to have high intracellular and extracellular protein and lipid content (Duong et al., 2015; Rasala and Mayfield, 2015; Schulze et al., 2016). Many sulfur containing amino acids and proteins such as cysteine and GSH have been shown to increase in concentration when marine algae are exposed to increased light intensity (Dupont et al., 2004), consistent with the increase in \%S reported by HRMS at both extreme light conditions. Carbohydrate abundances increased with photoperiod for both $C$. reinhardtii and $C$. vulgaris $(p<0.05)$ but plateaued for S. obliquus from $16: 8$ to $20: 4 \mathrm{~h}$ (Figure 2D). Across all species, a significant $(p<0.05)$ increase in carbohydrate material was observed at 20:4 when compared to 12:12 growth conditions. The increase in carbohydrate abundance was likely due to the degradation of algal cell walls during periods of oxidative stress induced by light (Aluwihare et al., 1997). The presence of aliphatic compounds at lower light regimes was also reinforced by the significantly greater $\% \mathrm{H}$ contribution at $12: 12 \mathrm{~h}$ and the greater $\% \mathrm{O}$ contribution at 20:4 h (Figures S7B,C; $p<0.05$ ). $\% \mathrm{~N}$ was significantly 

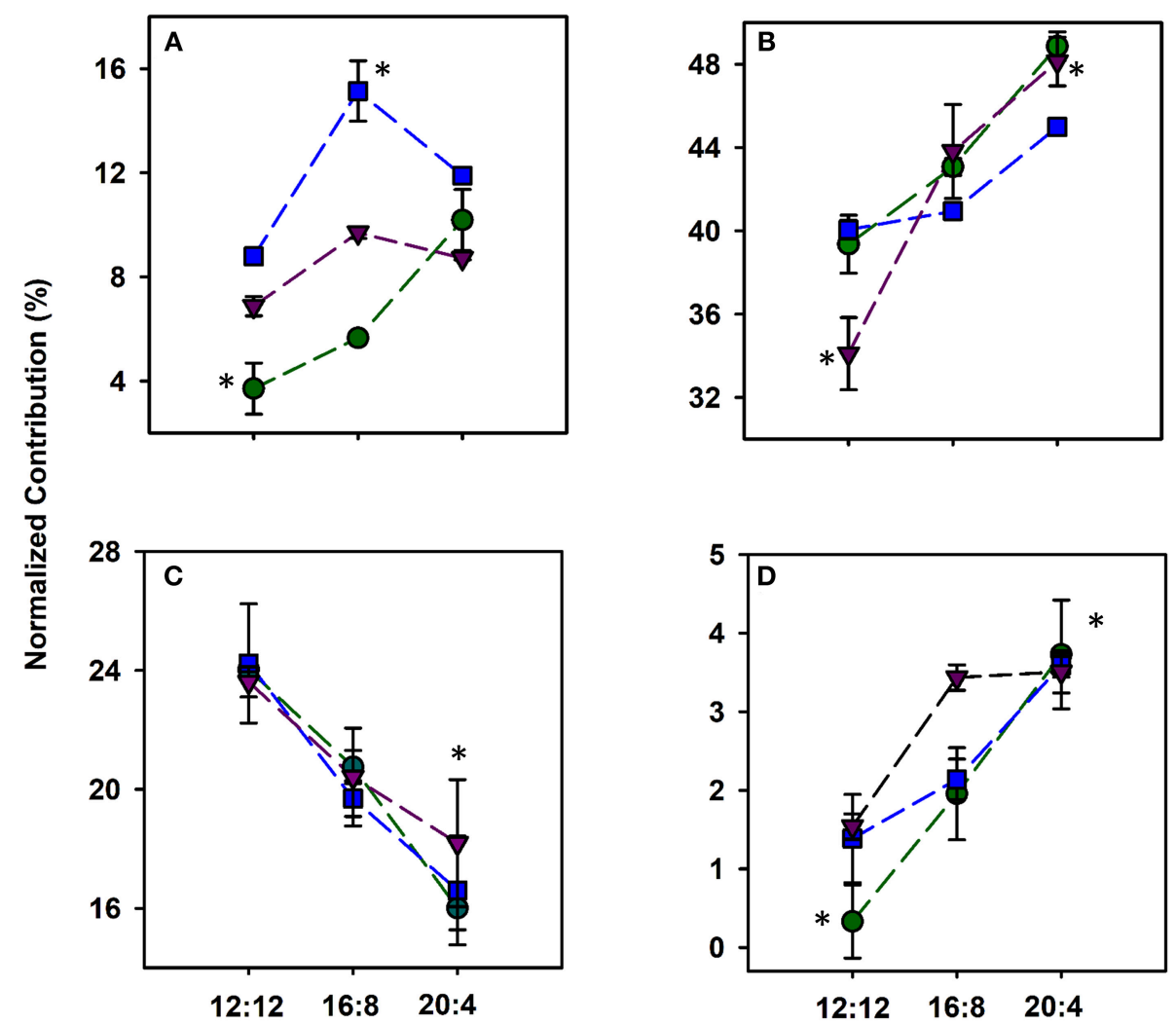

Light: Dark (Hours)

FIGURE 2 | Compound classes based on van Krevelen diagrams protraying the normalized relative abundance (\%) of lignin (A), protein (B), lipids (C), and carbohydrates (D) DOM released by C. vulgaris (blue), C. reinhardtii (green) and S. obliquus (purple) from $12 \mathrm{~h}$ light: 12 dark to $20 \mathrm{~h}$ light: $4 \mathrm{~h}$ dark. Error bars for all light:dark cycles are based on biological triplicates $(n=3)$. * Represent a signficant difference $(p<0.05)$ in compound classes between $12: 12$ and $20: 4 \mathrm{~h}$ for each algae.

greater at 12:12 when compared to all other growth conditions (Figure S7D; $p<0.05$ ) and when coupled to the increase in aliphatic material suggests that these constituents may contribute to the total protein and lipid pool of organic matter that have known to be released by algae as metabolic byproducts during instances of stress (Pirastru et al., 2012; Holguin and Schaub, 2013; Thornton, 2014; Mangal et al., 2016). While released DOM composition varied based on algal taxa, a higher light exposure led to an overall increase in molecules that are generally more aliphatic and polar in structure. Protein and carbohydraterich compounds were positively $(p<0.05)$ correlated whereas lipid content decreased as light exposure increased (Seyfabadi et al., 2011; Zhu et al., 2016).

\section{Hg-DOM Interactions}

\section{Hg-Cysteine}

$\mathrm{Hg}$ complexation was observed in the presence of model ligands, i.e., cysteine in a simple $\mathrm{MeOH}: \mathrm{H}_{2} \mathrm{O}$ matrix. Among the $6 \mathrm{Hg}$ containing formulas, ${ }^{202} \mathrm{HgC}_{6} \mathrm{H}_{13} \mathrm{~N}_{2} \mathrm{O}_{4} \mathrm{~S}_{2}$ was experimentally (Figure S6A) identified in the $\mathrm{Hg}$-cysteine sample (1:2 molar ratio) in positive mode and consistent with the theoretical isotopic distribution natural abundances (Figure S6B). The experimentally derived spectra revealed the most abundant isotopes ${ }^{202} \mathrm{Hg}$ and ${ }^{200} \mathrm{Hg}$ differed by -2.25 and $-2.26 \mathrm{ppm}$ from the theoretical distribution, respectively. The peak intensity ratio between ${ }^{202} \mathrm{Hg}$ and ${ }^{200} \mathrm{Hg}$ was $0.81: 1$ for the detected $\mathrm{Hg}$ Cys complex, comparable to the natural isotopic ratio of $0.77: 1$ using a 15T Fourier transform ion cyclotron mass spectrometer (FT ICR MS) (Chen et al., 2017). To further reinforce accurate formula assignment, $\mathrm{C}_{13}$ and $\mathrm{S}_{34}$ isotopes of the carbon-based ligand were also identified. While the exact mass of $\mathrm{Hg}$ isotopes in other studies incorporating a 15T FT ICR MS achieved $\pm 1 \mathrm{ppm}$ (Herlemann et al., 2014; Chen et al., 2017), our results suggest that $\mathrm{Hg}$ isotopes can be reasonably identified with confidence using Orbitrap mass spectrometry.

\section{Changes in Hg Binding DOM Composition With Varying Photoperiods}

Spectra of algal-derived DOM were similar before and after $\mathrm{Hg}$ addition suggesting limited ion suppression using ESI 


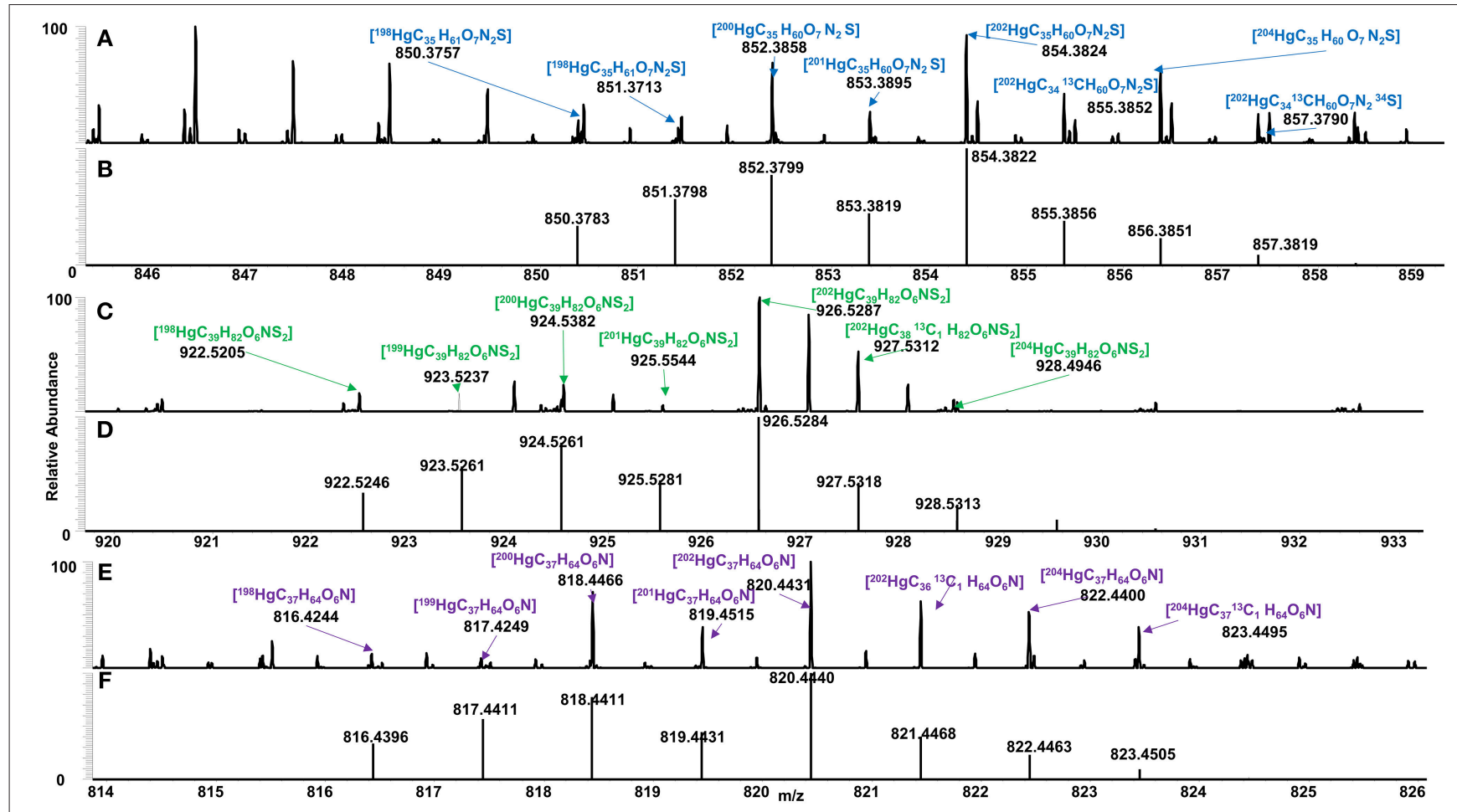

FIGURE 3 | Identified Hg binding DOM for (A) C. vulgaris (blue), (C) C. reinhardtii (green), and (E) S. obliquus (purple), and their respective theoretical isotopic distribution (B,D,F), based on exact mass, isotopic conformation, Winnow score and ${ }^{202} \mathrm{Hg}:{ }^{200} \mathrm{Hg}$ ratios.
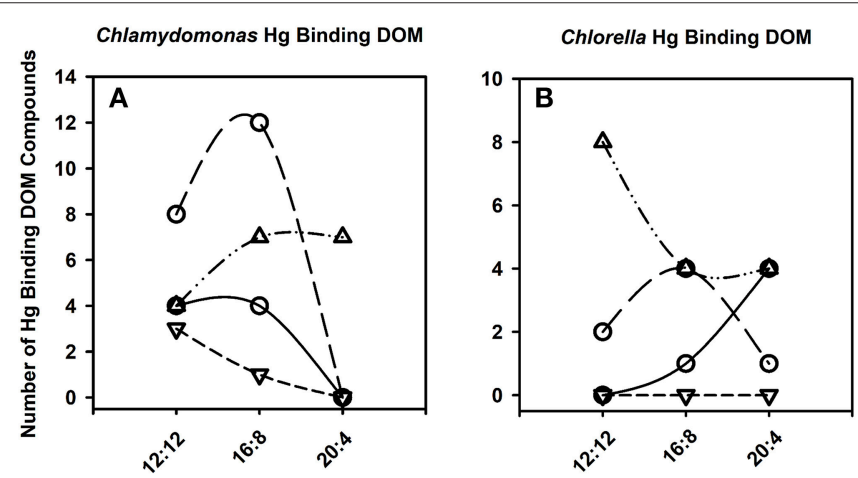

Scenedesmus Hg Binding DOM

Light to Dark Cycle (Hours)

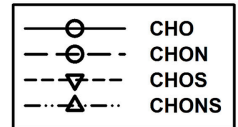

FIGURE 4 | Line and scatter plots portraying trends for generic Hg binding DOM formulas such as CHO (solid line, circles), CHON (long dash, circles), CHOS (short dash, downward triangles) and CHONS (dotted dash, triangles) for C. reinhardtii (A), C. vulgaris (B), and S. obliquus (C) as the duration of light exposure increases.

Orbitrap HRMS (Figures S3-S5,S10), congruent with previous studies (Chen et al., 2017). A total of 52, 28 and 19 Hg-DOM complexes were detected for C. reinhardtii, C. vulgaris, and $S$. obliquus, respectively, based on exact mass, theoretical $\mathrm{Hg}$ isotopic distribution, Winnow score (Doran and LeBlanc, 2016), and ${ }^{202} \mathrm{Hg}:{ }^{200} \mathrm{Hg}$ ratios (Figure 4). A total of 37,39 and $23 \mathrm{Hg}-\mathrm{DOM}$ complexes were found at 12:12, 16:8, and
$20: 4 \mathrm{~h}$, respectively which accounted for $1.6-2.6 \%$ of the total assigned peaks. The addition of $\mathrm{Hg}$ to algal DOM allowed for the identification of $\mathrm{Hg}$ isotopologues while retaining similar peaks in the metal free sample (Figure S9). Experimentally detected elemental formulas of $\left[{ }^{202} \mathrm{HgC}_{35} \mathrm{H}_{60} \mathrm{O}_{7} \mathrm{~N}_{2} \mathrm{~S}\right]$, $\left[{ }^{202} \mathrm{HgC}_{39} \mathrm{H}_{82} \mathrm{O}_{6} \mathrm{NS}_{2}\right]$, and $\left[{ }^{202} \mathrm{HgC}_{37} \mathrm{H}_{64} \mathrm{O}_{6} \mathrm{~N}\right]$ were validated based on ${ }^{200} \mathrm{Hg}$ and ${ }^{202} \mathrm{Hg}$ isotopes ratios. It can be noted 


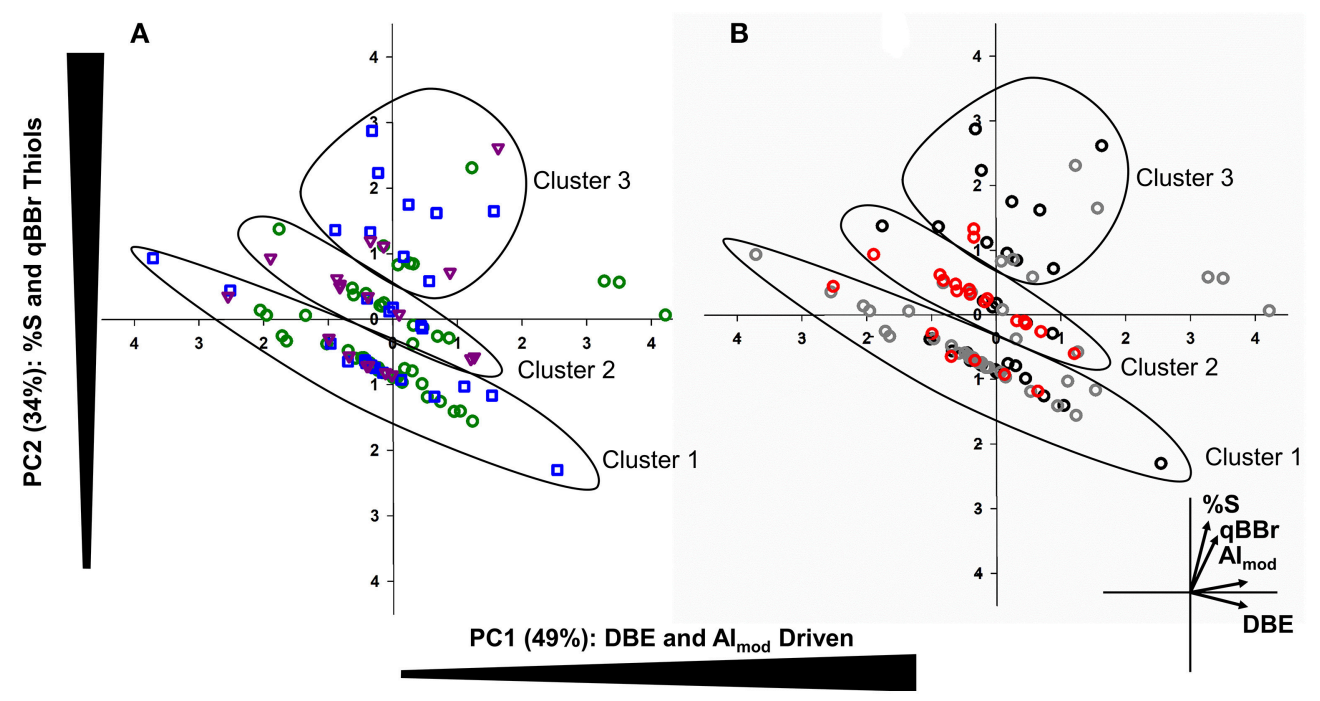

FIGURE 5 | Principal component analysis (PCA) combining bivariate and factor plots depicting compositional changes in Hg-DOM complexes based on algal species (A: green $=$ C. reinhardtii, blue $=$ C. vulgaris, and purple $=$ S. obliquus). The second PCA (B) also outlines Hg-DOM complexes, but colors indicate the light regime when $\mathrm{Hg}$-DOM compounds were found (black $=12: 12$, gray $=16: 8$, red $=20: 4$ ). In both plots, three distinct clusters were observed corresponding to similar Hg-DOM compounds along a DBE gradient.

that lower abundance $\mathrm{Hg}$ isotopes (i.e., ${ }^{196} \mathrm{Hg},{ }^{198} \mathrm{Hg},{ }^{201} \mathrm{Hg}$, and ${ }^{204} \mathrm{Hg}$ ) were also observed (Figures $3 \mathbf{A}-\mathbf{F}$ ) albeit at lower absolute intensities when compared to a $15 \mathrm{~T}$ FT ICR MS (Chen et al., 2017).

Differences in DOM composition at various growth periods can have an impact on the speciation of $\mathrm{Hg}$ by DOM. The number of $\mathrm{Hg}$ binding $\mathrm{CHO}, \mathrm{CHON}, \mathrm{CHOS}$ and $\mathrm{CHONS}$ varied with photoperiod and taxa (Figure 4). For example, the number of $\mathrm{CHO}$ binding $\mathrm{Hg}$ compounds was maximum at 16:8 across all taxa whereas the number of CHONS increased with photo exposure for $C$. reinhardtii and S. obliquus but decreased for $C$. vulgaris. The average $\mathrm{m} / z$ of $\mathrm{Hg}$-DOM complexes increased with photoperiod from 520 to $842 \mathrm{~m} / z$ and from 613 to $800 \mathrm{~m} / z$ for $C$. reinhardtii and S. obliquus, respectively, whereas smaller $m / z$ values were found at intermediate photoperiods (i.e., 16:8h) for C. vulgaris (612 vs. 867 and $729 \mathrm{~m} / z)$.

To assess how $\mathrm{Hg}$ binding DOM varies based on algal taxa and growth conditions, a PCA was conducted using $\% \mathrm{~S}, \mathrm{AI}_{\mathrm{mod}}$, $\mathrm{DBE}$, and $\mathrm{qBBr}$ equivalent thiol concentrations (Figure 5). The first principal component (PC1) indicative of $\mathrm{DBE}, \mathrm{AI}_{\text {mod }}$ driven variables explained $49 \%$ of variance whereas the second principal component (PC2) explained $34 \%$ of the variance and was strongly influenced by $\% \mathrm{~S}$ and $\mathrm{qBBr}$ equivalent thiol concentrations. Three distinct groups were observed that follow along a similar vector as $\mathrm{DBE}$, suggesting homologous $\mathrm{Hg}$ binding structures along a double bond gradient. Clusters 1 and 2 followed this pattern along a DBE vector and were comprised of 38 and $20 \mathrm{Hg}$ binding compounds, respectively. A final third cluster spanning from PC2 1 to 3 was less robust along the DBE gradient and had a greater contribution and influence of $\% \mathrm{~S}$ and $\mathrm{qBBr}$ reactive thiols. Sixteen $\mathrm{Hg}$ binding DOM compounds were associated with Cluster 3. No specific trends were observed between algal taxa, as each cluster contained a similar proportion of each species and overall species distributions were quite heterogenous (Figure 5A). When the PCA was organized based on light exposure (Figure 5B), the majority of 16:8 $\mathrm{Hg}$ binding compounds were found in the first cluster (57\%), where the second cluster is mainly comprised of compounds originating from 20:4 light dark samples (70\%). Finally, the 12:12 $\mathrm{Hg}$ binding DOM molecules in the final cluster influenced by $\% \mathrm{~S}$ and $\mathrm{qBBr}$ concentrations included $50 \%$ of the total DOM compounds.

A shift in light exposure from $16: 8 \mathrm{~h}$ to either $12: 12 \mathrm{~h}$ or $20: 4 \mathrm{~h}$ showed an increase in $\% \mathrm{~S}, \mathrm{qBBr}$ equivalent thiols, and the number of S-containing $\mathrm{Hg}$ binding compounds. With the availability of more sulfhydryl binding sites at both extremes of the photoperiods (Figure S7), a shift from amine and carboxyl functional groups to thiols may be observed, even at higher DOM:Hg ratios (Haitzer et al., 2002; Le Faucheur et al., 2014). Structural properties of released DOM are governed by the specific algal taxa as the only conserved $\mathrm{Hg}$ binding structure between algal taxa was $\mathrm{C}_{9} \mathrm{H}_{19} \mathrm{O}_{2} \mathrm{SHg}$ found during the 12:12 photoperiod of both C. reinhardtii and S. obliquus. As $\% \mathrm{~S}$ content increased, we observed more Hg-S structures at 20:4 and 12:12 that tend to have stronger binding affinities $(\log K>22)$ than the carboxyl functional groups ( $\log K>10)$ at 16:8 (Skyllberg and Drott, 2010; Chen et al., 2017). While assessing present thiol and sulfhydryl binding sites allows for predicting $\mathrm{Hg}$ complexation, the structure of the side chain attached to the sulfur containing group has important implications for the bioavailability of the complex (Le Faucheur et al., 2014; Leclerc et al., 2015). It has been shown that algal DOM abundant in low molecular weight thiols may act as a shuttle for $\mathrm{Hg}$ to bacteria, larger sinking algal DOM may facilitate $\mathrm{Hg}$ mobility to larger colloidal DOM fractions where $\mathrm{Hg}$ methylation readily occurs (Leclerc et al., 
2015; Schartup et al., 2015; Gascón Díez et al., 2016). A greater proportion of lower molecular weight compounds coupled to the increase in $\% \mathrm{~S}$ at $12: 12$ and to a lesser extent 20:4, suggests that early spring and later into the summer months may prompt periods of increased $\mathrm{Hg}$ bioavailability to smaller microorganisms whereas optimal light conditions of 16:8 for most algae may reduce $\mathrm{Hg}$ bioavailability. Smaller compounds are generally more easily uptaken by microorganisms, suggesting that Hg-binding DOM compounds produced by $C$. reinhardtii and S. obliquus at $12: 12 \mathrm{~h}$ can be internalized due to their smaller size coupled to the increase in $\% \mathrm{~S}$ and reactive thiols at 12:12 when compared to other light durations (Leclerc et al., 2015; Bravo et al., 2017).

Albeit important, the duration of photo exposure is not the only variable to consider when determining $\mathrm{Hg}$ complexation with algal DOM. Salinity, light intensity, $\mathrm{pH}$, and $\mathrm{DOM}$ concentration can all impact biogenic DOM composition and $\mathrm{Hg}$ binding to various functional groups within DOM. For example, an increase in DOM released by algae during changing photoperiods is likely due to an increased carbon fixation rate when compared to optimal diurnal growing conditions (Cherrier et al., 2015). Relationships between DOC concentration released by algae and light exposure have been reported in temperate regions (Mueller et al., 2016) wherein longer photoperiod exposures have been shown to prompt an increase in the hydrogen metabolism cycle leading to greater hydrogen exudation, and higher DOC concentrations in C. reinhardtii cultures (Oncel and Sukan, 2011). In natural systems, these changes in DOC concentrations, natural variation in light intensity, and additional physiochemical properties may further impact the composition of released DOM and thus metal binding properties (McIntyre and Guéguen, 2013).

\section{CONCLUSION}

In this study, we applied HESI Orbitrap HRMS to explore compositional differences between various algae cultivated across a photo exposure gradient and how these compositional changes can impact DOM-Hg complexation. Increasing the growth photoperiod led to an overall increase in protein and carbohydrate DOM being released by all algae. Conversely, the lipid content significantly decreased as photo exposure increased, in line with previous studies (Zhu et al., 2016). Of all cultivated algae, S. obliquus produced the greatest \%S and potential thiol structures when cultivated at a $12: 12 \mathrm{~h}$ light:dark photoperiod, reinforced by both HRMS and $\mathrm{qBBr}$ titrations. While taxonomical differences across algae played an important role in $\mathrm{Hg}$ binding, the duration of light exposure significantly altered algal derived DOM composition and thus influenced $\mathrm{Hg}$ complexation. Lower photoperiods enhanced \%S and $\mathrm{qBBr}$ reactive thiol production allowing for the production

\section{REFERENCES}

Aluwihare, L. I., Repeta, D. J., and Chen, R. F. (1997). A major biopolymeric component to dissolved organic carbon in the surface sea water. Nature 387, 166-169. doi: $10.1038 / 387166 \mathrm{a} 0$ of unique CHONS and CHOS compounds more aliphatic in nature that may result in the increased bioavailability of $\mathrm{Hg}$ DOM compounds. Our results emphasize that Orbitrap HRMS can be used for both (1) the untargeted characterization of complex algal biomolecules as cultivation methods vary and (2) the identification of $\mathrm{Hg}$ isotopes within a complex matrix to determine $\mathrm{Hg}$-NOM speciation information.

Although further studies incorporating MS/MS are needed to accurately quantify and confirm definitive Hg-DOM structures, the use of Orbitrap HRMS can be utilized for the preliminary identification of $\mathrm{Hg}$ binding DOM molecules. We suggest that a similar methodological approach using Orbitrap HRMS be utilized to explore how other cultivation variables such as $\mathrm{pH}$, salinity, light intensity, and other algal species can all impact $\mathrm{Hg}-\mathrm{DOM}$ complexation. The role of algal DOM in controlling $\mathrm{Hg}$ fate is continuously advancing and the approaches utilized in this study provide novel insights into the profound role that algal DOM has on the $\mathrm{Hg}$ complexation in aquatic systems.

\section{AUTHOR CONTRIBUTIONS}

VM, TP, and TN conducted the experiments. VM, TP, and CG analyzed the data. All authors contributed to writing the manuscript.

\section{FUNDING}

This work was funded by the Canada Research Chairs Program (CG), the Natural Sciences and Engineering Research Council of Canada (NSERC; CG, VM), the Ontario Graduate Scholarship (VM), the Weston Garfield Award for Northern Research (Doctoral) (VM), and the Trent University Symons Trust Fund (VM).

\section{ACKNOWLEDGMENTS}

The authors would like to thank Dr. Naomi Stock and Dr. Michael Doran for their assistance with Orbitrap and Winnow troubleshooting. We are also thankful for Antoine Perroud for his assistance with DOC analyses and Dr. Paul-Philippe Champagne for his constructive feedback. Finally, many thanks to the two reviewers for their constructive feedback during the peer review process.

\section{SUPPLEMENTARY MATERIAL}

The Supplementary Material for this article can be found online at: https://www.frontiersin.org/articles/10.3389/fenvs. 2018.00155/full\#supplementary-material

Andersson, M. E., Sommar, J., Gardfeldt, K., and Lindqvist, O. (2008). Enhanced concentrations of dissolved gaseous mercury in the surface waters of the Arctic Ocean. Mar. Chem. 3-4, 190-194. doi: 10.1016/j.marchem.2008.04.002

Ansotegui, A., Sarobe, A., Trigueros, J. M., Urrutxurtu, I., and Orive, E. (2003). Size distribution of algal pigments and algal 
assemblages in a coastal-estuarine environment: contribution of small eukaryotic algae. J. Plank. Res. 25, 341-355. doi: 10.1093/plankt/ 25.4.341

Bhatia, M. P., Das, S. B., Longnecker, K., Charette, M. A., and Kujawinski, E. B. (2010). Molecular characterization of dissolved organic matter associated with the Greenland ice sheet. Geochim. Cosmochim. Acta. 74, 3768-3784. doi: 10.1016/j.gca.2010.03.035

Bravo, A. G., Bouchet, S., Tolu, J., Bjorn, E., Mateos-Rivera, A., and Bertilsson, S. (2017). Molecular composition of organic matter controls methylmercury formation in boreal lakes. Nat. Commun. 8:14255. doi: 10.1038/ncomms14255

Bronk, D. A., See, J. H., Bradley, P., and Killberg, L. (2007). DON as a source of bioavailable nitrogen for algal. Biogeosciences 4, 283-296. doi: 10.5194/bg-4-283-2007

Chen, H., Johnston, R. C., Mann, B. F., Chu, R. K., Tolic, N., Parks, J. M., et al. (2017). Identification of mercury and dissolved organic matter complexes using ultrahigh resolution mass spectrometry. Environ. Sci. Technol.. 4, 59-65. doi: 10.1021/acs.estlett.6b00460

Chen, J., Gu, B., LeBoeuf, E. J., Pan, H., and Dai, S. (2002). Spectroscopic characterization of the structural and functional properties of natural organic matter fractions. Chemosphere 48, 59-68. doi: 10.1016/S0045-6535(02)00041-3

Cherrier, J., Valentine, S. K., Hamill, B., Jeffrey, W. H., and Marra, J. F. (2015). Light-mediated release of dissolved organic carbon by algal. J. Mar. Syst. 147, 45-51. doi: 10.1016/j.jmarsys.2014.02.008

D’Andrilli, J., Foreman, C. M., Marshall, A. G., and McKnight, M. D. (2013). Characterization of IHSS Pony Lake fulvic acid dissolved organic matter by electrospray ionization Fourier transform ion cyclotron resonance mass spectrometry and fluorescence spectroscopy. Org. Geochem. 65, 19-28. doi: 10.1016/j.orggeochem.2013.09.013

Doran, M. C., and LeBlanc, K. L. (2016). A computer program to simplify analysis of mass scan data of organometallic compounds from high resolution mass spectrometers. Rapid Commun. Mass Spectrom. 30, 2561-2567. doi: $10.1002 / \mathrm{rcm} .7748$

Duong, V. T., Ahmed, F., Thomas-Hall, S. R., Quigley, S., Nowak, E., and Schenk, P. M. (2015). High protein- and high lipid-producing microalgae from northern Australia as potential feedstock for animal feed and biodiesel. Front. Bioeng. Biotechnol. 3:53. doi: 10.3389/fbioe.2015. 00053

Dupont, C. L., Goepfert, T. J., Lo, P., Wei, L., and Ahner, B. A. (2004). Diurnal cycling og glutathione in marine algal: field and culture stuides. Limnol. Oceanogr. 49, 991-996. doi: 10.4319/lo.2004.49. 4.0991

Frost, B. W. (1987). Grazing control of algal stock in the open subarctic Pacific Ocean: a model assessing the role of mesozooplankton, particularly the large calanoid copepods Neocalanus spp. Mar. Ecol. Prog. Ser. 39, 49-68. doi: $10.3354 /$ meps039049

Gascón Díez, E., Loizeau, J. L., Cosio, C., Bouchet, S., Adatte, T., Amouroux, D., et al. (2016). Role of settling particles on mercury methylation in the oxic water column of freshwater systems. Environ. Sci. Technol. 50, 11672-11679. doi: 10.1021/acs.est.6b03260

Guschina, I. A., and Harwood, J. L. (2006). Lipids and lipid metabolism in eukaryotic algae. Prog. Lipid Res. 45, 160-186. doi: 10.1016/j.plipres.2006.01.001

Haitzer, M., Aiken, G. R., and Ryan, J. N. (2002). Binding of Hg to DOM the role of the Hg DOM ratio. Environ. Sci. Technol. 46, 2715-2723. doi: 10.1021/es025699i

Herlemann, D. P. R., Manecki, M., Meeske, C., Pollehne, F., Labrenz, M., SchulzBull, D., et al. (2014). Uncoupling of bacterial terrigenous dissolved organic matter dynamics in decomposition experiments. PLoS ONE 9:e0093945. doi: 10.1371/journal.pone.0093945

Hernes, P. J., Robinson, A. C., and Aufdenkampe, A. K. (2007). Fractionation of lignin during leaching and sorption and implications for organic matter "freshness". Geophys. Res. Lett. 34, 1-6. doi: 10.1029/2007GL031017

Herzsprung, P., Hertkorn, N., Tumpling, W. V., Harir, M., Friese, K., and Schmitt-Kopplin, P. (2016). Molecular forumula assignment for dissolved organic matter (DOM) using high-field FT-ICR-MS: chemical perspective and validation of sulphur-rich organic components (CHOS) in pit lake samples. Anal. Bioanal. Chem. 408, 2461-2469. doi: 10.1007/s00216-0169341-2
Holguin, F. O., and Schaub, T. (2013). Characterization of microalgal lipid feedstock by direct infusion FT ICR mass spectrometry. Algal Res. 2, 43-50. doi: 10.1016/j.algal.2012.11.005

Joe-Wong, C., Shoenfelt, E., Hauser, J. E., Crompton, N., and Myneni, C. B. S. (2012). Estimation of reactive thiol concentrations in dissolved organic matter and bacterial cell membranes in aquatic systems. Environ. Sci. Technol. 46, 9854-9861. doi: 10.1021/es301381n

Kellerman, A. M., Kothawala, D. N., Dittmar, T., and Tranvik, L. J. (2015). Persistence of dissolved organic matter in lakes related to its molecular characteristics. Nat. Geosci. 8, 454-457. doi: 10.1038/ngeo2440

Kim, S., Kramer, R. W., and Hatcher, P. G. (2003). Graphical method for analysis of ultrahigh-resolution broadband mass spectra of natural organic matter, the van Krevelen diagram. Anal. Chem. 75, 5336-5344. doi: 10.1021/ac034415p

Koch, B. P., and Dittmar, T. (2006). From mass to structure: an aromaticity index for high-resolution mass data of natural organic matter. Rapid Commun. Mass Spectrom.. 20 , 926-932. doi: 10.1002/rcm.2386

Lancelot, C. (1984). Extracellular release of small and large molecules by algal in the southern Bight of the North Sea. Estuar. Coast. Shelf Sci. 18, 65-77. doi: 10.1016/0272-7714(84)90007-6

LaPerriere, J. D., Tilsworth, T., and Casper, L. A. (1978). Nutrient Chemistry of a Large, Deep Lake in Subarctic Alaska. Corrvalis, OR: U.S. Environmental Protection Agency. Available online at: https://scholarworks.alaska.edu/ handle/11122/1226 (Accessed December 18, 2018).

Larose, C., Dommergue, A., De Angelis, M., Cossa, D., Averty, B., Marusczak, N., et al. (2010). Springtime changes in snow chemistry lead to new insights into mercury methylation in the Arctic. Geochim. Cosmochim. Acta 74, 6263-6275. doi: 10.1016/j.gca.2010.08.043

Lavoie, R. A., Jardine, T. D., Chumchal, M. M., Kidd, K. A., and Campbell, L. M. (2013). Biomagnification of mercury in aquatic food webs: a worldwide meta-analysis. Environ. Sci. Technol. 47, 13385-13394. doi: 10.1021/es403103t

Le Faucheur, S., Campbell, P. G. C., Fortin, C., and Slaveykova, V. I. (2014). Interactions between mercury and algal: speciation, bioavailability, and internal handling. Environ. Toxicol. Chem. 33, 1211-1224. doi: 10.1002/etc.2424

Le, S., Josse, J., and Husson, F. (2008). FactoMineR: An R package for multivariate analysis. J. Stat. Softw. 25, 1-18. doi: 10.18637/jss.v025.i01

Leclerc, M., Planas, D., and Amyot, M. (2015). Relationship between extracellular low-molecular-weight thiols and mercury species in natural lake periphytic biofilms. Environ. Sci. Technol. 49, 7709-7716. doi: 10.1021/es505952x

Legendre, P. (2014). Imodel2: Model II Regression. R Package. v.1.7-2. Available online at: https:/CRAN.R-project.org/package=lmodel2 (Accessed December 18, 2018).

Lehnherr, I., St. Louis, V. L., Hintelmann, H., and Kirk, J. L. (2011). Methylation of inorganic mercury in polar marine waters. Nat. Geosci. 4, 298-302. doi: 10.1038/ngeo1134

Leu, E., Mundy, C. J., Assmy, P., Campbell, K., Gabrielsen, T. M., Gosselin, M., et al. (2015). Arctic spring awakening - steering principles behind the phenology of vernal ice algal blooms. Proc. Natl. Acad. Sci. U.S.A. 139, 151-170. doi: 10.1016/j.pocean.2015.07.012

Leya, T., Rahn, A., Lutz, C., and Remias, D. (2009). Response of arctic snow and permafrost algae to high light and nitrogen stress by changes in pigment composition and applied aspects for biotechnology. FEMS Microbiol. Ecol. 67, 432-443. doi: 10.1111/j.1574-6941.2008.00641

Mangal, V., and Guéguen, C. (2015). Examining concentrations and molecular weights of thiols in microorganism cultures and in Churchill River (Manitoba) using a fluorescent-labeling method coupled to asymmetrical flow field-flow fractionation. Anal. Bioanal. Chem. 407, 4305-4313. doi: 10.1007/s00216-015-8599-0

Mangal, V., Shi, X. Y., and Gueguen, C. (2017). Compositional changes and molecular transformations of dissolved organic matter during the arctic spring floods in the lower Churchill watershed (Northern Manitoba, Canada). Biogeochem 136, 151-165. doi: 10.1007/s10533-017-0388-8

Mangal, V., Stock, N. L., and Guéguen, C. (2016). Molecular characterization of algal dissolved organic matter (DOM) and sulphur components using high resolution Orbitrap mass spectrometry. Anal. Bioanal. Chem. 408, 1891-1900. doi: $10.1007 / \mathrm{s} 00216-015-9295-9$

Maranon, E., Cermeno, P., and Perez, V. (2005). Continuity in the photosynthetic production of dissolved organic carbon from eutrophic to oligotrophic waters. Mar. Ecol. Prog. Ser. 299, 7-17. doi: 10.3354/meps 299007 
Martone, P. T., Estevez, J. M., Lu, F., Ruel, K., Denny, M. W., Somerville, C., et al. (2009). Discovery of lignin in seaweed reveals convergent evolution of cell-wall architecture. Curr. Biol. 19 , 169-175. doi: 10.1016/j.cub.2008.12.031

McIntyre, A. M., and Guéguen, C. (2013). Binding interactions of algalderived dissolved organic matter with metal ions. Chemosphere 90, 620-626. doi: 10.1016/j.chemosphere.2012.08.057

Monier, A., Comte, J., Babin, M., Forest, A., Matsuoka, A., and Lovejoy, C. (2015). Oceanographic structure drives the assembly processes of microbial eukaryotic communities. ISME J. 9, 990-1002. doi: 10.1038/ismej.2014. 197

Mueller, B., Haan, J., Visser, P. M., Vermeij, M. J. A., and Duyl, F. C. (2016). Effect of light and nutrient availability on the release of dissolved organic carbon (DOC) by Caribbean turf algae. Sci. Rep. 6:23248. doi: 10.1038/srep23248

Ngu-Schwemlein, M., Lin, X., Rudd, B., and Bronson, M. (2014). Synthesis and ESI mass spectrometric analysis of the association of mercury(II) with multi-cysteinyl peptides. J. Inorg. Biochem. 133, 8-23. doi: 10.1016/j.jinorgbio.2013.12.008

Ohno, T., and Ohno, P. E. (2013). Influence of heteroatom pre-selection on the molecular formula assignment of soil organic matter components determined by ultrahigh resolution mass spectrometry. Anal. Bioanal. Chem. 405, 3299-3306. doi: 10.1007/s00216-013-6734-3

Oncel, S., and Sukan, F. V. (2011). Effect of light intensity and the light: dark cycles on the long term hydrogen production of Chlamydomonas reinhardtii by batch cultures. Biomass Bioenergy. 35, 1066-1074. doi: 10.1016/j.biombioe.2010.11.017

Osterholz, H., Kirchman, D. L., Niggemann, J., and Dittmar, T. (2016). Environmental drivers of dissolved organic matter molecular composition in the Delaware Estuary. Front. Earth Sci. 4:95. doi: 10.3389/feart.2016.00095

Park, J. S., Oh, S., Shin, M. Y., Kim, M. K., Yi, S. M., and Zoh, K. D. (2008). Seasonal variation in dissolved gaseous mercury and total mercury concentrations in Juam Reservoir, Korea. Environ. Pollut. 154, 12-120. doi: 10.1016/j.envpol.2007.12.002

Parks, J. M., John, A., Podar, M., Bridou, R., Hurt, R. A., Smith, S. D., et al. (2013). The genetic basis for bacterial mercury methylation. Science 339, 1332-1335. doi: 10.1126/science.1230667

Pirastru, L., Perreault, F., Chu, F. L., Oukarroum, A., Sleno, L., Popovic, R., et al. (2012). Long-term stress induced by nitrate deficiency, sodium chloride, and high light on photosystem II activity and carotenogenesis of green alga Scenedesmus sp. Botany 90, 1007-1014. doi: 10.1139/b2012-077

Rasala, B. A., and Mayfield, S. P. (2015). Photosynthetic biomanufacturing in green algae; production of recombinant proteins for industrial, nutritional, and medical uses. Photosyn. Res. 123, 227-239. doi: 10.1007/s11120-014-9994-7

Riedel, T., Biester, H., and Dittmar, T. (2012). Molecular fractionation of dissolved organic matter with metal salts. Environ. Sci. Technol. 46, 4419-4426. doi: 10.1021/es203901u

Roth, V. N., Dittmar, T., Gaupp, R., and Gleixner, G. (2013). The molecular composition of dissolved organic matter in forest soils as a function of $\mathrm{pH}$ and temperature. PLoS ONE 10:e0119188. doi: 10.1371/journal.pone.0119188

Roth, V. N., Dittmar, T., Gaupp, R., and Gleixner, G. (2015). Latitude and pH driven trends in the molecular composition of DOM across a north south transect along the Yenisei River. Geochim. Cosmochim. Acta 123, 93-105. doi: 10.1016/j.gca.2013.09.002

Sadiq, I. M., Pakrashi, S., Chandrasekaran, N., and Mukerjee, M. (2011). Studies of toxiciity of aluminum oxide $\left(\mathrm{Al}_{2} \mathrm{O}_{3-}\right)$ nanoparticles to microalgae species: Scenedesmus sp and Chlorella sp. J. Nanopart. Res. 13, 3287-3299. doi: 10.1007/s11051-011-0243-0

Schartup, A. T., Ndu, U., Balcom, P. H., Mason, R. P., and Sunderland, E. M. (2015). Contrasting effects of marine and terrestrially derived dissolved organic matter on mercury speciation and bioavailability in seawater. Environ. Sci. Technol. 49, 5965-5972. doi: 10.1021/es506274x

Schulze, C., Reinhardt, J., Wurster, M., Ortiz-Tena, J. G., Sieber, V., and Mundt, S. (2016). A one-stage cultivation process for lipid- and carbohydraterich biomass of Scenedesmus obtusiusculus based on artificial and natural water sources. Bioresour. Technol. 218, 498-504. doi: 10.1016/j.biortech.2016. 06.109
Seyfabadi, J., Ramexanpour, Z., and Khoeyi, A. Z. (2011). Protein, fatty acid, and pigment content of Chlorella vulgaris under different light regimes. J. Appl. Phycol. 23 , 721-726. doi: 10.1007/s10811-010-9569-8

Sipler, R. E., Kellogg, C. T. E., Connelly, T. L., Roberts, Q. N., Yager, P. L., and Bronk, D. A. (2017). Microbial community response to terrestrially derived dissolved organic matter in the coastal Arctic. Front. Microbiol. 8:1018. doi: $10.3389 /$ fmicb.2017.01018

Skyllberg, U., and Drott, A. (2010). Competition between disorder iron sulfide and natural organic matter associated thiols for mercury (II)-an EXAFS study. Environ. Sci. Technol. 44, 1254-1259. doi: 10.1021/es902091w

St. Louis, V. L., Hintelmann, H., Graydon, J. A., Kirk, J. L., Barker, J., Dimock, B., et al. (2007). Methylated mercury species in canadian high arctic marine surface waters and snowpacks. Environ. Sci. Technol. 41, 6433-6441. doi: 10.1021/es070692s

Sueoka, N. (1960). Mitotic replication of deoxyribonucleic acid in Chlamydomonas Reinhardi. Proc. Natl. Acad. Sci. U.S.A. 46, 83-91.

Thornton, D. C. O. (2014). Dissolved organic matter (DOM) release by algal in the contemporary and future ocean. Eur. J. Phycol. 49, 20-46. doi: 10.1080/09670262.2013.875596

Tian, J., and Yu, J. (2009). Changes in ultrastructure and responses of antioxidant systems of algae (Dunaliella salina) during acclimation to enhanced ultraviolet-B radiation. J. Photochem. Photobiol. B Biol. 97, 152-160. doi: 10.1016/j.jphotobiol.2009.09.003

Tremblay, L. B., Dittmar, T., Marshall, A. G., Cooper, W. J., and Cooper, W. T. (2007). Molecular characterization of dissolved organic matter in a North Brazilian mangrove porewater and mangrove-fringed estuaries by ultrahigh resolution Fourier Transform-Ion Cyclotron Resonance mass spectrometry and excitation/emission spectroscopy. Mar. Chem. 105, 15-29. doi: 10.1016/j.marchem.2006.12.015

Van Grrest, G. J., Spierenburg, P., Van Donk, E., and Hessen, D. O. (2007). Daphnia growth rates in arctic ponds: limitation by nutrients or carbon? Polar Biol. 30, 235-242. doi: 10.1007/s00300-006-0177-7

Wada, S., and Hama, T. (2013). The contribution of macroalgae to the coastal dissolved organic matter pool. Estuar. Coast. Shelf Sci. 129, 77-85. doi: 10.1016/j.ecss.2013.06.007

Wang, K., Munson, K. M., Beaupre-Laperriere, A., Mucci, A., Macdonald, R. W., and Wang, F. (2018). Subsurface seawater methylmercury maximum explains biotic mercury concentrations in the Canadaian Arctic. Sci. Rep. 8, 1-5. doi: 10.1038/s41598-018-32760-0

Waska, H., Koschinsky, A., and Dittmar, T. (2016). Fe- and Cu-complex formation with artificial ligands investigated by ultra-high resolution FourierTransform ion Cyclotron Resonance Mass Spectrometry (FT-ICR-MS): Implications for natural metal-organic complex studies. Front. Mar. Chem. 3:119. doi: 10.3389/fmars.2016.00119

Winder, M., and Sommer, U. (2012). Algal response to a changing climate. Hydrobiol 698, 5-16. doi: 10.1007/s10750-012-1149-2

Yamada, E., Ohara, S., Uehara, T., Hirota, T., Hatori, N., Fuse, Y., et al. (2012). Biodegradation of dissolved organic matter released from phytoplanktoon in Lake Biwa. Anal. Sci. 28, 675-681. doi: 10.2116/analsci.28.675

Zhu, L. D., Li, Z. H., and Hiltunen, E. (2016). Strategies for lipid production improvement in microalgae as a biodisel feedstock. BioMed Res. Int. 2016:8792548. doi: 10.1155/2016/8792548

Conflict of Interest Statement: The authors declare that the research was conducted in the absence of any commercial or financial relationships that could be construed as a potential conflict of interest.

Copyright (c) 2019 Mangal, Phung, Nguyen and Guéguen. This is an open-access article distributed under the terms of the Creative Commons Attribution License (CC $B Y)$. The use, distribution or reproduction in other forums is permitted, provided the original author(s) and the copyright owner(s) are credited and that the original publication in this journal is cited, in accordance with accepted academic practice. No use, distribution or reproduction is permitted which does not comply with these terms. 